\title{
Effects of age, nursing, and oral IGF1 supplementation on neonatal porcine cervical development
}

\author{
Meredith E Camp, Anne A Wiley ${ }^{1}$, Monica B Boulos, Kathleen M Rahman, Frank F Bartol ${ }^{1, *}$ \\ and Carol A Bagnell
}

Department of Animal Sciences, Endocrinology and Animal Biosciences Program, Rutgers University, Foran Hall, 59 Dudley Road, New Brunswick, New Jersey 08901, USA and ${ }^{1}$ Department of Anatomy, Physiology and Pharmacology, Cellular and Molecular Biosciences Program, Auburn University, Auburn, Alabama 36849, USA

Correspondence should be addressed to C A Bagnell; Email: bagnell@aesop.rutgers.edu

${ }^{*}$ (F F Bartol and C A Bagnell contributed equally to this work)

\begin{abstract}
Nursing supports neonatal porcine uterine and testicular development, however, lactocrine effects on cervical development are undefined. Studies were conducted to determine the effects of i) age and the imposition of the lactocrine-null state from birth (postnatal day 0 (PND0)) by milk replacer feeding on cervical histology; ii) imposition of the lactocrine-null state for 2 days from birth on cervical cell proliferation, as reflected by proliferating cell nuclear antigen immunostaining; and iii) a single feeding of colostrum or milk replacer, administered at birth, with or without oral IGF1, on cervical cell proliferation and phosphorylated AKT (pAKT) and B-cell lymphoma 2 (BCL2) protein levels at $12 \mathrm{~h}$ postnatal. Cervical crypt depth and height of luminal epithelium (LE) increased with age by PND14, when both responses were reduced in replacer-fed gilts. Cell proliferation was reduced in LE at PND2, and in crypt epithelium and stroma by PND14 in replacer-fed gilts. Returning replacer-fed gilts to nursing on PND2 did not rescue the cervical phenotype by PND14. A single feeding of colostrum, but not milk replacer, was sufficient to support cervical cell proliferation at $12 \mathrm{~h}$ postnatal. IGF1 supplementation induced cell proliferation in replacer-fed gilts, and increased cervical pAKT and BCL2 levels in colostrum-fed gilts and replacer-fed gilts at $12 \mathrm{~h}$ postnatal. Results indicate that age and nursing support porcine cervical development, support is initiated at first ingestion of colostrum, IGF1 may be lactocrine-active, and identification of lactocrine-active factors can be accomplished by $12 \mathrm{~h}$ postnatal using this bioassay system.

Reproduction (2014) 148 441-451
\end{abstract}

\section{Introduction}

In mammals, maternal influence on neonatal development continues after birth through lactation and nursing (Peaker 2002). Nursing supports development of the neonatal porcine reproductive tract by delivering milkborne bioactive factors (MbFs) from mother to offspring as proposed in the lactocrine hypothesis (Yan et al. 2006, Bartol et al. 2008). In the neonatal pig, lactocrine signaling is important for uterine (Miller et al. 2013) and testicular (Rahman et al. 2014) development. However, the extent to which age and nursing affect cervical histogenesis during the early postnatal period is unknown. Histologically, the adult porcine cervix is lined by columnar luminal epithelium (LE) and contains epithelial crypts that penetrate the adluminal stroma (St; Eldridge-White et al. 1989, Winn et al. 1993). Features of neonatal porcine uterine development are defined more completely with respect to both patterns of endometrial histogenesis (Bartol et al. 1993) and periods of postnatal life, during which disruption of the uterine developmental program can affect the organizational trajectory and, ultimately, phenotype of the endometrium (Tarleton et al. 2001). For the porcine uterus, imposition of the lactocrine-null state for $48 \mathrm{~h}$ from birth (postnatal day 0 (PND0)), by feeding milk replacer in lieu of nursing, alters patterns of endometrial development (Miller et al. 2013). Effects of imposition of the lactocrine-null condition on the uterus, detected as early as PND2, were pronounced by PND14 (Miller et al. 2013).

Colostrum (first milk) contains bioactive factors including relaxin, a prototypical MbF (Frankshun et al. 2011), detected in the circulation of nursed pigs by $12 \mathrm{~h}$ postnatal (Yan et al. 2006). Insulin-like growth factor 1 (IGF1; $7.6 \mathrm{kDa})$, another member of the insulin family of hormones, is found in porcine colostrum at high concentrations (Simmen et al. 1990a, Donovan \& Odle 1994, Donovan et al. 1994), which decline within the first $24-36 \mathrm{~h}$ of lactation during the transition from colostrum to mature milk (Klobasa et al. 1987, 
Neville et al. 2001, Nguyen et al. 2001). In the porcine neonate, a window for transmission of macromolecules, including MbFs, is open before gut closure, which is estimated to occur within $48 \mathrm{~h}$ of birth (Leece 1973). Orally administered IGF1 is locally bioactive in neonatal pigs, promoting intestinal crypt cell proliferation and increasing villus height (Xu et al. 1994, Burrin et al. 1996, Houle et al. 2000). Whether oral IGF1 affects somatic tissue development beyond the gastrointestinal (GI) tract is unknown. IGF1 signaling can act via the phosphatidylinositol-3 kinase (PI3K)/AKT pathway (Tseng et al. 2002, Shelton et al. 2004) to promote cell proliferation, differentiation, and survival (Baserga \& Rubin 1993). A serine/threonine kinase (Shelton et al. 2004), AKT, activated when phosphorylated AKT (pAKT), increases the levels of the anti-apoptotic protein B-cell lymphoma 2 (BCL2) (Mora et al. 2005). Thus, broadly, pAKT and BCL2 can be used as indicators of IGF1mediated signaling.

Three studies were conducted to evaluate the extent to which age and imposition of the lactocrine-null state from birth (PND0), as well as oral IGF1 supplementation, affect the patterns of cervical development in the neonatal gilt. The objective of study 1 was to determine the effects of age and imposition of the lactocrine-null state from birth through milk replacer feeding on cervical histology at PND2 and PND14. The objective of study 2 was to determine the effects of imposition of the lactocrine-null state (i.e. absence of nursing) for 2 days from birth on patterns of cervical cell proliferation at PND2 and PND14. Finally, study 3 was designed to determine whether a single feeding of colostrum, as compared with milk replacer, administered at birth, with or without supplemental IGF1, affects cell behaviors associated with cervical development when assessed at $12 \mathrm{~h}$ postnatal. Evidence of such comparatively shortterm effects would support establishment of a more efficient bioassay protocol for identification of lactocrine-active factors.

\section{Materials and methods}

\section{Animals}

Crossbred gilts (Sus scrofa domesticus; Duroc, Hampshire, Yorkshire, and Landrace genetics) were obtained from the swine unit of the New Jersey Agricultural Experiment Station, Rutgers University or the Auburn University Swine Research and Education Center. At birth, gilts, born from sows at their first to fourth parity, were assigned randomly to nurse normally from their dams or to be fed porcine milk replacer (Milk Specialties Global, Carpentersville, IL, USA). Replacer-fed gilts were kept in a separate pen in the same environment and in close proximity to their dams. All pens were equipped with heat lamps. Gilts admitted to these studies had a minimum birth weight of $1.3 \mathrm{~kg}$, based on evidence that postnatal development is retarded in lower body weight piglets (Rehfeldt \& Kuhn 2006). Three studies were conducted as outlined in
A

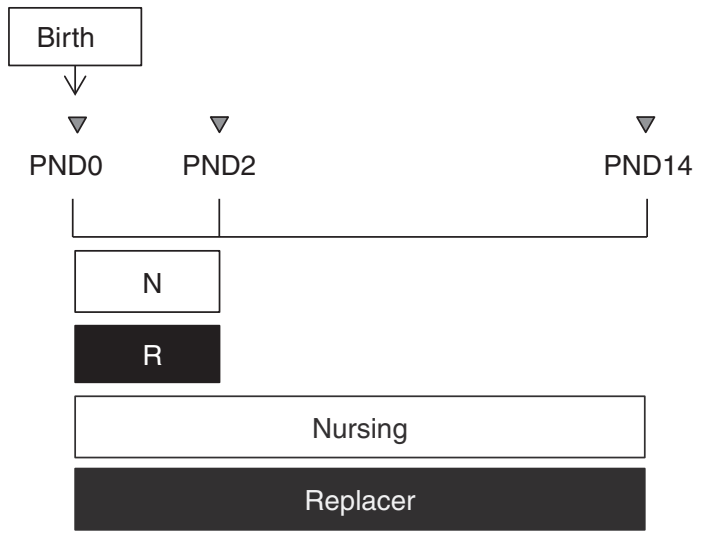

B
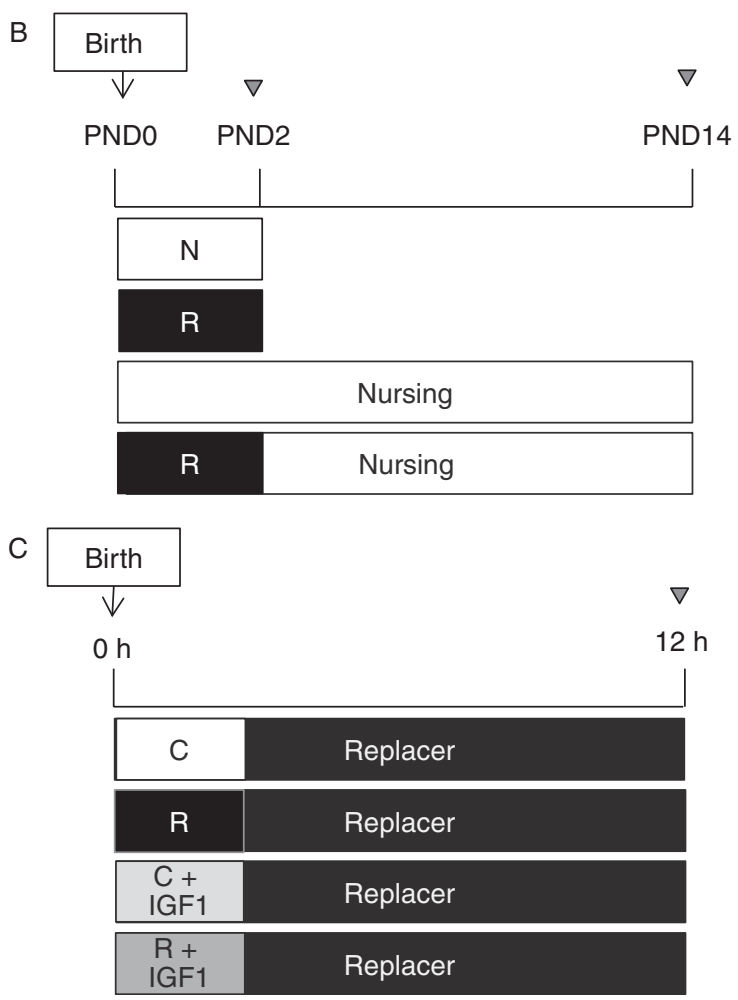

Figure 1 Experimental designs for (A) study 1 ; (B) study 2; and (C) study 3. Tissues were obtained at birth (PND0), before nursing, or gilts were allowed to either nurse $(\mathrm{N})$ ad libitum or were fed milk replacer $(\mathrm{R})$ from birth to PND2 or PND14. Oral IGF1 study 3 gilts (C) were gavage-fed a single feeding of colostrum $(\mathrm{C})$ or milk replacer at birth, with or without IGF1, followed by milk replacer feeding until $12 \mathrm{~h}$ postnatal when tissues were collected. Cervices were obtained at time points as indicated by arrowheads; $n=5-10 /$ group.

Fig. 1. In all studies, care was taken to insure that treatments were balanced for potential effects of litter $(n=22$ litters for the cervical histoarchitecture study (Fig. 1A); $n=12$ litters for the cell proliferation study (Fig. 1B); and $n=6$ litters for the IGF1 study (Fig. 1C)). Nursing groups were normalized by number of offspring and male siblings were not removed.

Study 1 was conducted to determine the effects of age and nursing from birth on the patterns of cervical histogenesis at PND2 and PND14 (Fig. 1A). In this study, the gilts were either 
euthanized at birth $(n=10)$, before nursing, nursed ad libitum from birth to PND2 $(n=7)$ or PND14 $(n=6)$, or gavage-fed milk replacer $(30 \mathrm{ml} / \mathrm{kg}$ body weight $(\mathrm{BW})$ per $2 \mathrm{~h}$ ) from birth to PND2 $(n=5)$ or PND14 $(n=5)$. The milk replacer dosages followed published recommendations (Houle et al. 2000). The cervices were collected on PND0, PND2, or PND14.

Study 2 was conducted to determine the effects of replacer feeding for 2 days from birth on cervical cell proliferation and histology at PND2 and PND14 (Fig. 1B). Here, gilts were either: i) nursed ad libitum from birth to PND2 $(n=7)$; ii) gavage-fed milk replacer from birth to PND2 $(n=5)$; iii) nursed ad libitum from birth to PND14 $(n=5)$; or 4) gavage-fed milk replacer for $48 \mathrm{~h}$ from birth and then switched to nursing until PND14 $(n=6)$. Tissues were collected on PND2 and PND14.

Study 3 was conducted to determine the effects of colostrum or replacer feeding at birth, with or without oral IGF1, on cervical development at $12 \mathrm{~h}$ postnatal (Fig. 1C). At birth, gilts ( $n=4-5 /$ group) were gavage-fed a single volume $(15 \mathrm{ml} / \mathrm{kg}$ BW) of either i) colostrum collected at the onset of parturition (0 h lactation); ii) colostrum supplemented with recombinant human IGF1 ( $1 \mu \mathrm{g} / \mathrm{ml}$; Prepro Tech, Rocky Hill, NJ, USA); iii) milk replacer alone; or iv) milk replacer supplemented with IGF1 $(1 \mu \mathrm{g} / \mathrm{ml})$. The dose of IGF1 used in these studies was based on the concentration of IGF1 found in porcine colostrum as reported elsewhere (Simmen et al. 1990a). After the initial feeding, all gilts were gavage-fed milk replacer $(30 \mathrm{ml} / \mathrm{kg} \mathrm{BW}$ per $2 \mathrm{~h}$ ) until $12 \mathrm{~h}$, then they were euthanized and tissues were collected.

All procedures involving animals were reviewed and approved by relevant Institutional Animal Care and Use Committees and were conducted in accordance with the Guide for the Care and Use of Agriculture Animals in Research and Teaching (2010; Federation of Animal Science Societies, Champaign, IL, USA).

\section{Histology and histomorphometry}

At the time of tissue collection, the cervices were trimmed of excess connective tissue, fixed in Xpress Molecular Fixative (Sakura Finetek, Torrance, CA, USA) or 4\% paraformaldehyde and embedded in Paraplast Plus (Sigma-Aldrich, St. Louis, MO, USA). Preliminary experiments comparing fixatives used on tissues at the same time point showed no difference on either hematoxylin and eosin or proliferating cell nuclear antigen (PCNA) staining. Cross sections of cervical tissues $(6 \mu \mathrm{m})$ were affixed to Superfrost Plus slides (VWR International, LLC, Radnor, PA, USA). The tissues were deparaffinized, rehydrated, stained with Immunomaster hematoxylin (American Master Tech Scientific, Lodi, CA, USA), and counterstained with eosin (Fisher Scientific, Fair Lawn, NJ, USA). General histological observations and measurements were made in four to five nonsequential sections per gilt using an Olympus FSX100 microscope at $4.2 \times$ and $20 \times$ magnifications. As shown in Fig. 2, cervical crypt depth for all crypts (both deep and shallow) in each section was measured from the basal aspect of LE in the cervical crypt to the mouth of the crypt at the lumen. Porcine cervical crypts were defined as columnar epithelia forming distinct folds that protrude from the lumen. Assessment of cervical luminal epithelial height was determined by measuring

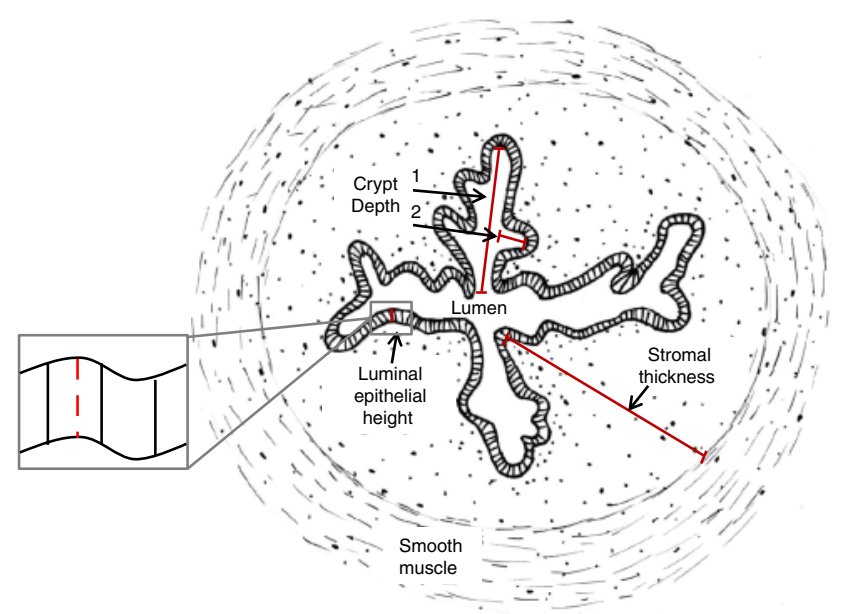

Figure 2 Schematic of the neonatal porcine cervix (cross section) illustrating the histomorphometric protocol employed to obtain the measurements of luminal epithelial, crypt depth, and stromal thickness. Red lines show how depth of (1) deep and (2) shallow cervical crypts was measured from the basal aspect of the LE to the mouth of the crypt at the lumen. Magnified inset shows how height of the cervical LE was measured from the basal aspect to the apical surface of LE. Stromal thickness was measured from the basal border of the LE to the interface of stroma and the inner smooth muscle layer.

from the basal aspect to the apical surface of LE. A minimum of ten LE sites were chosen at random for each cervical tissue section (Ryan etal. 2001). Stromal thickness was measured from the basal border of the LE to the interface of St and the inner circular smooth muscle layer. Four quadrants were identified for each cervical cross-section and one measurement was made at random in each quadrant of each section.

\section{Immunohistochemistry}

Immunostaining to detect PCNA in situ was carried out using a VectaStain ABC Elite Kit (Vector Laboratories, Burlingame, CA, USA). The cervical sections were subjected to antigen retrieval in boiling sodium citrate buffer $(\mathrm{pH}=6)$, blocked with normal horse serum at room temperature, and incubated with mouse anti-rat PCNA IgG (1:100; $0.91 \mu \mathrm{g} / \mathrm{ml}$; Invitrogen Life Technologies) overnight at $4{ }^{\circ} \mathrm{C}$. After incubation with biotinylated secondary antibody, endogenous peroxidase activity was blocked (3\% hydrogen peroxide for $5 \mathrm{~min}$ at room temperature) and sections were incubated with $A B C$ reagent and developed using $0.1 \%$ diaminobenzidine substrate (Santa Cruz Biotechnology, Dallas, TX, USA). Negative control sections were incubated with mouse isotype control IgG $(1.06 \mu \mathrm{g} / \mathrm{ml}$; Invitrogen). The images were obtained using a QImaging camera and analyzed using ImageJ Software (National Institute of Health, Bethesda, MD, USA).

\section{PCNA labeling index}

Digital images $(10 \times$ magnification) of PCNA-stained cervical tissues were converted to 8-bit grayscale using Adobe Photoshop (CS5 Version 12.1; Adobe Systems, Inc.). The nuclei were identified as positive when staining intensity values were at or 
above $30 \%$ of the highest values generated by Image (Masters et al. 2007, Miller et al. 2013). For LE, crypt epithelium (CE), and St, a minimum of 1000 cells (labeled and unlabeled) were counted for each gilt. Grayscale images were converted to pseudocolor using Imagej in order to better illustrate staining intensity. In this study, positively stained cells appear yellowgreen on a black background. For each cell compartment (CE, LE, and St), a PCNA labeling index (LI), expressed as a percentage, was determined by dividing the number of PCNA-positive cells by the total number of cells counted and multiplying that value by 100 (Masters et al. 2007, Miller et al. 2013).

\section{Protein extraction and immunoblot analysis}

Total cervical protein was extracted by homogenizing tissues (20 mg) in lysis buffer (1\% Triton X-100, 10\% glycerol, $150 \mathrm{mM}$ Tris- $\mathrm{HCl}, 300 \mathrm{mM} \mathrm{NaCl}$, and $1 \mathrm{mM} \mathrm{MgCl} 2, \mathrm{pH}=7.5)$. The samples were centrifuged $\left(12000 \mathrm{~g} / 4^{\circ} \mathrm{C} / 10 \mathrm{~min}\right)$ and the protein supernatant was removed and stored at $-80^{\circ} \mathrm{C}$. Protein concentrations were measured using the DC Protein Assay Kit (Bio-Rad Laboratories, Hercules, CA, USA). Cervical proteins $(20 \mu \mathrm{g})$ were resolved on $12 \%$ total monomer, Bis-Tris- $\mathrm{HCl}$ buffered polyacrylamide gels (Invitrogen) under reducing conditions, followed by transfer onto nitrocellulose membranes (Bio-Rad Laboratories). The membranes were blocked with 10\% nonfat milk powder (NFMP) in Tris-buffered saline containing Tween (TBST; $25 \mathrm{mM}$ Tris (pH=7.5), $0.14 \mathrm{mM} \mathrm{NaCl}, 3 \mathrm{mM} \mathrm{KCl}$, and $0.05 \%$ Tween 20 ) for $1 \mathrm{~h}$ at room temperature. The membranes were incubated with rabbit anti-mouse pAKT (1:1000; 60 kDa; Cell Signaling, Beverly, MA, USA) in TBST$5 \%$ NFMP overnight at $4{ }^{\circ} \mathrm{C}$. The membranes were then washed with TBST and incubated with HRP-conjugated goat anti-rabbit secondary antibody (1:10 000; Invitrogen) for $1 \mathrm{~h}$ at room temperature. After washing in TBST, the membrane-bound antibodies were detected by ECL (Perkin Elmer Life Sciences, Waltham, MA, USA) on film, as per manufacturer recommendations. The membranes were washed with stripping buffer (Restore Western Blotting Stripping Buffer, Thermo Scientific, Waltham, MA, USA) to remove antibodies. To ensure that all antibodies were removed after stripping, ECL was added and membranes were developed using film to confirm that no signal was present. The membranes were then incubated with rabbit anti-mouse AKT (1:1000; 60 kDa; EMD Millipore, Burlington, MA, USA) overnight at $4{ }^{\circ} \mathrm{C}$, washed with TBST, and incubated with goat anti-mouse IgG (1:10 000; Invitrogen) for $1 \mathrm{~h}$ at room temperature. Signal was detected using ECL and film. Lastly, the membranes were probed with rabbit anti-human BCL2 (1:1000; 26 kDa; sc-492, Santa Cruz Biotechnology) overnight at $4{ }^{\circ} \mathrm{C}$, washed with TBST, and incubated with goat anti-rabbit IgG (1:10 000; Invitrogen) for $1 \mathrm{~h}$ at room temperature. The pAKT controls were lysates $(10 \mu \mathrm{g})$ from bovine mammary epithelial cells (MAC-T) incubated with ( + control) or without ( - control) IGF1 (Fleming et al. 2006). The BCL2-positive control lysate was human BCL2-transfected 293T cells $(10 \mu \mathrm{g}$; sc-176463; Santa Cruz Biotechnology). Protein loading was monitored using total AKT. For AKT, pAKT, and BCL2, antibody specificity was evaluated by omission of primary antibodies in the immunoblot analysis. Incubation with secondary antibody alone showed no evidence of cross reactivity with cervical proteins.
Chemiluminescence signals were quantified densitometrically from the film using Scion Image for Windows (Scion Corp., Frederick, MD, USA). All data were corrected for background signals and expressed as target protein to total AKT ratio.

\section{Statistical analyses}

Quantitative data were subjected to the analyses of variance using GLM procedures (SAS 2013, Cary, NC, USA) and are presented as least squares means (LSM) \pm s.E.M. For studies 1 and 2 analyses considered variation due to the main effects of treatment (nursing vs replacer), age, and cell compartment (epithelium vs St), as well as interactions as appropriate. For study 3 , analyses considered variation due to the main effects of a single feeding of colostrum or milk replacer with or without oral IGF1 (colostrum vs replacer feeding; colostrum alone vs colostrum + IGF1; and replacer alone vs replacer+IGF1).

\section{Results}

\section{Study 1: effects of age and nursing on cervical histoarchitecture}

The effects of neonatal age on cervical luminal epithelial height, crypt depth, and stromal thickness are shown in Fig. 3. Both luminal epithelial height (Fig. 3A) and crypt depth (Fig. 3B) were similar on PND0 and PND2, and increased $(P<0.001)$ by PND14. Stromal thickness was not affected by age.

Figure 4 shows the effects of neonatal age and milk replacer feeding on cervical histoarchitecture. Overall, both luminal epithelial height and crypt depth increased $(P<0.001)$ from PND2 to PND14. Imposition of the lactocrine-null state from birth by replacer feeding reduced $(P<0.001)$ luminal epithelial height and crypt depth by PND14, when treatment effects were most pronounced (treatment $\times$ day, $P<0.001$ ). In contrast, stromal thickness was unaffected by either age or treatment.

Cervical histology on PND0 and PND14 in nursed and replacer-fed gilts is shown in Fig. 5. Cervical crypt development advanced from PND0 to PND14 and was most pronounced in nursed gilts in which, compared with replacer-fed gilts, more extensive branching of cervical crypts was observed by PND14. Cervices from replacer-fed gilts obtained on PND14 were histologically similar to the tissues obtained on PND0.

\section{Study 2: effects of age and nursing on cervical cell proliferation}

Pseudocolored images showing the effects of nursing for 2 days from birth on PCNA immunostaining patterns and histograms depicting PCNA LI data for cervical tissues obtained on PND2 and PND14 are shown in Fig. 6. Signal indicative of PCNA labeling above background was observed in all cell compartments. On PND2, cervical histology of nursed gilts (Fig. 6A) was similar to that of replacer-fed gilts (Fig. 6B). However, the 

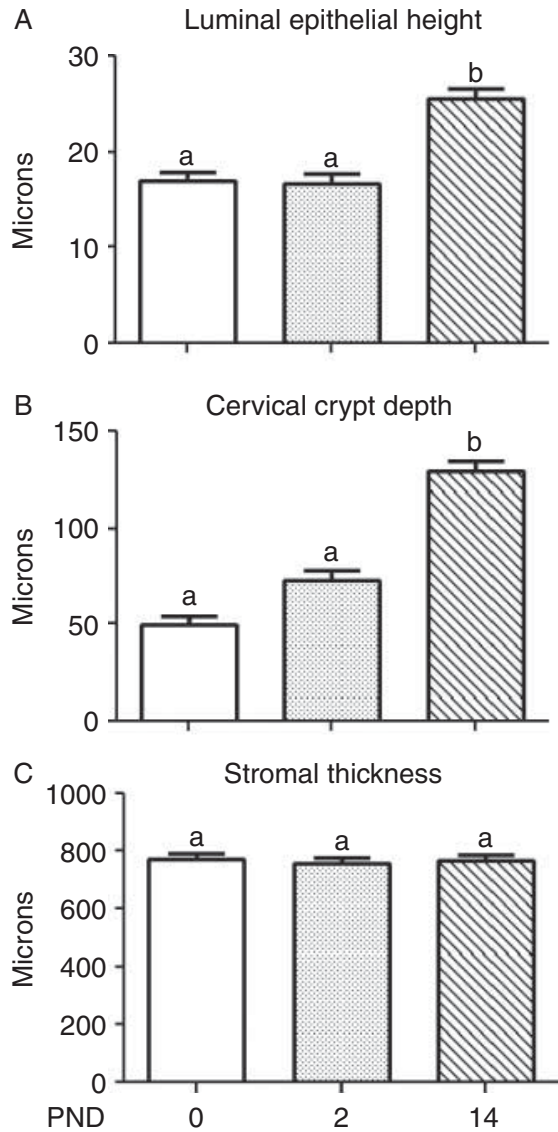

Figure 3 Effects of age on neonatal porcine cervical (A) luminal epithelial height, (B) crypt depth, and (C) stromal thickness. Data are expressed as LSM \pm s.E.M. Different letters denote differences $(P<0.001)$.

imposition of the lactocrine-null state for 2 days from birth reduced $(P<0.05)$ PCNA LI compared with nursed gilts (Fig. 6C) by PND2. Overall, in nursed and replacerfed gilts, PCNA LI was lower $(P<0.01)$ in epithelium (LE and CE) when compared with St on PND2. This effect was most pronounced for LE (treatment $\times$ cell compartment, $P<0.05$ ).

Generally, in comparison with gilts nursed for 2 weeks from birth, cervical development on PND14 was retarded in replacer-fed gilts that returned to nursing on PND2 (Fig. 6D vs E). Overall, PCNA LI was lower $(P<0.001)$ in epithelium than in St (Fig. 6F), and higher $(P<0.05)$ in nursed as compared with replacer-fed gilts. Reduced PCNA LI associated with the imposition of the lactocrinenull condition for 2 days from birth was most pronounced in CE and St (treatment $\times$ cell compartment, $P<0.05$ ).

\section{Study 3: effects of a single feeding of colostrum or milk replacer, with or without oral IGF1, on cervical cell proliferation at $12 \mathrm{~h}$ postnatal}

Images showing the effects of a single feeding of colostrum or milk replacer at birth, with or without IGF1, on cervical PCNA immunostaining patterns, and
PCNA LI at $12 \mathrm{~h}$ postnatal are shown in Fig. 7. In comparison with gilts given a single feeding of colostrum at birth, replacer feeding alone was associated with a marked reduction in PCNA immunostaining at $12 \mathrm{~h}$ (Fig. 7A vs B). Colostrum-fed gilts showed similar PCNA immunostaining patterns with or without oral IGF1 (Fig. 7A vs C). In contrast, IGF1 supplementation for replacer-fed gilts resulted in cervical immunostaining patterns similar to those observed for colostrum-fed gilts (Fig. 7D vs A and C). These observations were reflected by data for PCNA LI (Fig. 7E, F and G). For cervical LE $(P<0.01)$, CE $(P<0.001)$, and St $(P<0.05)$, PCNA LI at $12 \mathrm{~h}$ postnatal was reduced in replacer-fed gilts compared with colostrum-fed gilts. The colostrum-fed gilts supplemented with IGF1 showed similar PCNA LIs compared with those observed for gilts fed colostrum alone in all cervical compartments. However, when replacer-fed gilts were supplemented with IGF1, PCNA $\mathrm{LI}$ for $\mathrm{LE}, \mathrm{CE}$, and St were increased in comparison with gilts fed replacer alone $(P<0.01)$, and were comparable with those observed for colostrum-fed gilts, with or without supplemental IGF1.
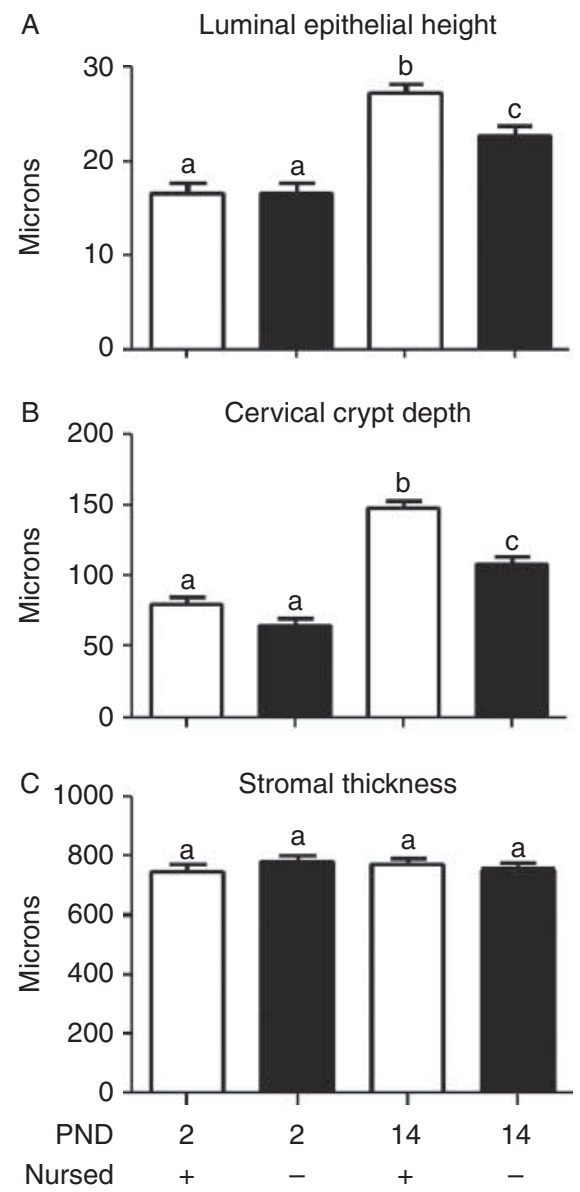

Figure 4 Effects of nursing $(+)$ or milk replacer feeding $(-)$ and neonatal age on (A) luminal epithelial height, (B) crypt depth, and (C) stromal thickness. Data are expressed as LSM \pm s.E.M. Different letters denote differences $(P<0.01)$. 


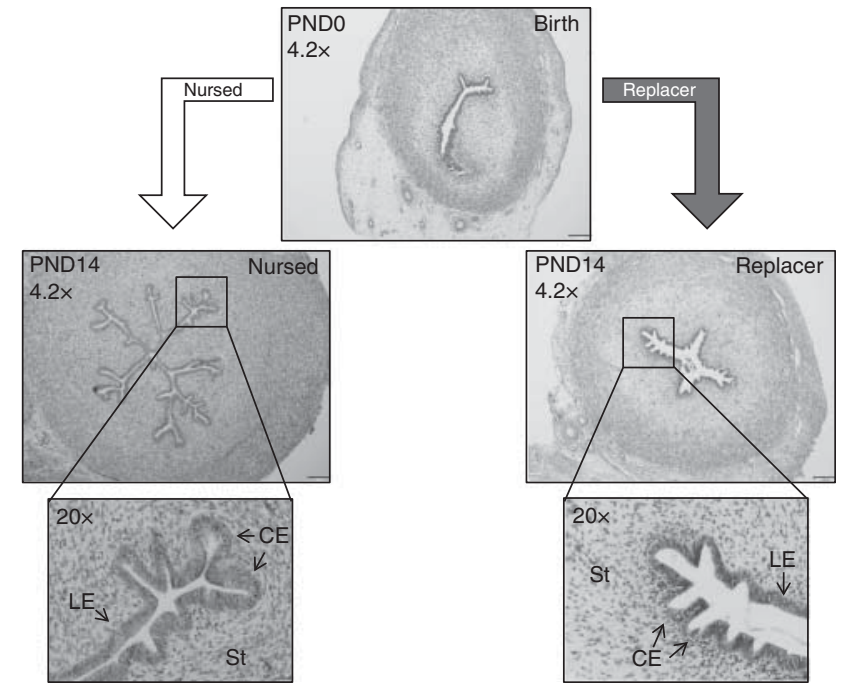

Figure 5 Cervical histoarchitecture affected by age and nursing. Photomicrographs of porcine cervical tissues obtained at birth (PND0; top) and from nursed (left) as compared with replacer-fed (right) gilts on PND14. Low-power images $(4.2 \times$; bar $=153 \mu \mathrm{m})$ and high-power detailed $(20 \times$; bar $=32 \mu \mathrm{m})$ images illustrate the effects of both age (PND0 vs PND14) and imposition of the lactocrine-null condition from birth by replacer feeding on cervical histology. Crypt epithelium (CE), $\mathrm{LE}$, and stroma (St) are indicated in $20 \times$ images.

\section{Study 3: effects of a single feeding of colostrum or milk replacer, with or without oral IGF1, on cervical $B C L 2$ and $P A K T$ proteins at $12 \mathrm{~h}$ postnatal}

A representative immunoblot image showing BCL2, pAKT, and total AKT proteins at $12 \mathrm{~h}$ postnatal in cervical protein lysates from colostrum-fed gilts or replacer-fed gilts, with or without oral IGF1, is shown in Fig. 8A. Immunoreactive BCL2 (26 kDa), pAKT $(60 \mathrm{kDa})$, and AKT $(60 \mathrm{kDa})$ proteins were detected in all cervical tissues. Colostrum-fed gilts and replacer-fed gilts showed comparable expression of BCL2 protein. However, oral supplementation of IGF1 in colostrum-fed gilts increased cervical BCL2 $(P<0.05)$ levels when compared with control gilts fed colostrum alone. Likewise, replacer-fed gilts supplemented with IGF1 had higher cervical BCL2 $(P<0.05)$ protein levels when compared with gilts fed replacer alone (Fig. 8B). Cervical pAKT protein levels were similar in gilts fed colostrum or replacer alone. Cervical pAKT levels increased $(P<0.001)$ in colostrum-fed gilts supplemented with IGF1 when compared with gilts fed colostrum alone. Similarly, IGF1-supplemented, replacer-fed gilts had increased $(P<0.001)$ pAKT protein levels when compared with gilts fed only replacer (Fig. 8C).

\section{Discussion}

Results confirm and extend previous findings for the porcine uterus (Miller et al. 2013) and testes (Rahman et al. 2014), by showing the effects of age and nursing on cervical development that are evident on or before PND14. New observations were presented regarding porcine cervical histogenesis that illustrate the effects of imposition of the lactocrine-null state for 2 days from birth on cellular and molecular aspects of cervical development in the neonate. Furthermore, results indicate that a single feeding of colostrum at birth affects events associated with cervical development that are detectable by $12 \mathrm{~h}$ postnatal, and that such effects can be mimicked by oral IGF1 supplementation in the neonatal pig.

In nursed pigs, events associated with cervical histogenesis reported in this study include age-related increases in crypt depth, luminal epithelial height, and branching of crypts into the cervical St. The results indicate that, as observed for the uterus (Miller et al. 2013), cervical histology does not change appreciably between birth and PND2, and that cervical crypt depth and luminal epithelial height increase with age by PND14. However, as observed for endometrial gland development in the neonatal pig (Miller et al. 2013), cervical crypt development was retarded on PND14 in lactocrine-null gilts. In the adult pig, cervical crypts form interdigitations important for copulation, insemination, and fertility (Eldridge-White et al. 1989, Winn et al. 1993). Whether alterations in cervical development reported in this study for replacerfed gilts affect reproductive performance later in life has yet to be determined. However, a relationship between the

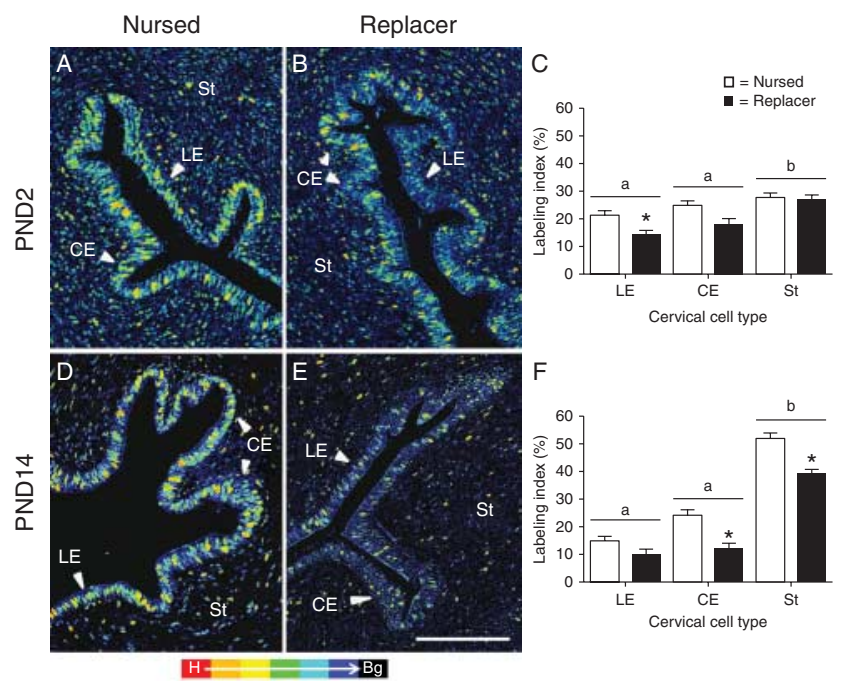

Figure 6 Effects of neonatal age and nursing on cervical PCNA immunostaining and PCNA labeling indices (LIs). Pseudocolored images illustrate PCNA labeling patterns in LE, crypt epithelium (CE), and stroma (St) for cervical tissues obtained on PND2 (A and B) and PND14 (D and E) from nursed (A and D) and replacer-fed ( $B$ and $E$ ) gilts. Positively, immunostained cells appear yellow-green on a black background; scale bar indicates $100 \mu \mathrm{m}$. Associated data for PCNA LI by cervical cell compartment are shown for PND2 (C) and PND14 (F). White bars denote nursed and black bars denote replacer-fed groups. Data are presented as LSM \pm S.E.M. Horizontal lines with different letters denote differences between cell compartments at PND2 $(P<0.01)$ and PND14 $(P<0.001)$. Asterisks denote cell compartment-specific treatment effects (nursed vs replacer) at PND2 and PND14 $(P<0.05)$. 

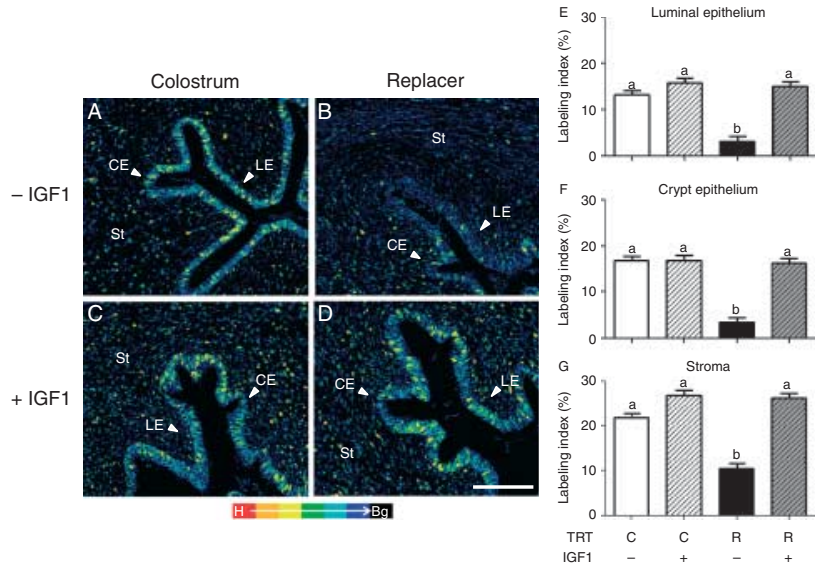

Figure 7 Effects of a single feeding of colostrum $(C)$ or milk replacer $(\mathrm{R})$, with $(+)$ or without $(-)$ oral IGF1, on cervical PCNA immunostaining patterns (A, B, C and D) and PCNA LI (E, F and G) at $12 \mathrm{~h}$ postnatal. Pseudocolored images illustrate PCNA labeling patterns in LE, CE, and St. Positively stained cells appear yellow-green on a black background; scale bar indicates $100 \mu \mathrm{m}$. For histograms, data are presented as LSM \pm S.E.M. and different letters denote differences (LE, $P<0.01$; CE, $P<0.001$; and St, $P<0.05)$.

amount of colostrum consumed by gilts on PND0 and their lifetime fecundity was documented (Bartol et al. 2013). In a retrospective study involving 381 sows, low serum immunoglobulin immunocrit values on their day of birth (Vallet et al. 2013), indicating minimal colostrum consumption, were associated with reduced litter size over four parities. Taken together, studies emphasize the importance of colostrum ingestion shortly after birth for the support of female reproductive tract (FRT) development. Mechanisms through which lactocrine programing of FRT development may affect reproductive capacity remain to be defined.

Targeted disruption of FRT development during organizationally critical periods of postnatal life can have lasting effects on the form and function of adult reproductive tissues (Crain et al. 2008, McLachlan et al. 2012). In the hamster, neonatal exposure to diethylstilbesterol increased cervical diameter and altered LE histology, reflected by increased luminal epithelial height and cornification, in a manner that persisted into adulthood (Hendry et al. 2004). In sheep (Bartol et al. 1999, Gray et al. 2001) and mice (Cooke et al. 2012, Filant et al. 2013), strategic neonatal exposure to progestins inhibited the development of uterine glands and suppressed fertility in adults. Such lasting effects are likely to reflect the disruption of postnatal organizational events that determine cell fate and, by consequence, morphogenetic processes that dictate tissue structure and function (Bartol \& Bagnell 2012).

Although cervical histology at PND2 was similar in nursed and replacer-fed gilts, reduced proliferation of LE was observed in replacer-fed gilts as reflected by PCNA LI. Treatment effects on the patterns of cervical LE proliferation were similar to those described for the PND2 porcine endometrium (Miller et al. 2013). Consistently, as observed for the neonatal porcine uterus (Miller et al. 2013), imposition of the lactocrine-null state from birth reduced PCNA LI in CE and St, but not in LE, on PND14. Collectively, results are consistent with the idea that lactocrine support is important for both cervical and endometrial development in the neonatal pig, and that mitogenic factors in colostrum support development (Donovan \& Odle 1994, Blum \& Baumrucker 2008).

Returning replacer-fed gilts to nursing on PND2 did not rescue the cervical phenotype by PND14. Again, results obtained for the cervix agreed with the observations reported for the developing porcine endometrium (Miller et al. 2013). Factors to be considered in explanation of these observations include potential interactions of $\mathrm{Gl}$ tract maturation with parallel changes in the composition of colostrum that are associated with its transition to mature milk. In the pig, gut closure occurs within 24-48 h of birth (Leece 1973). This event
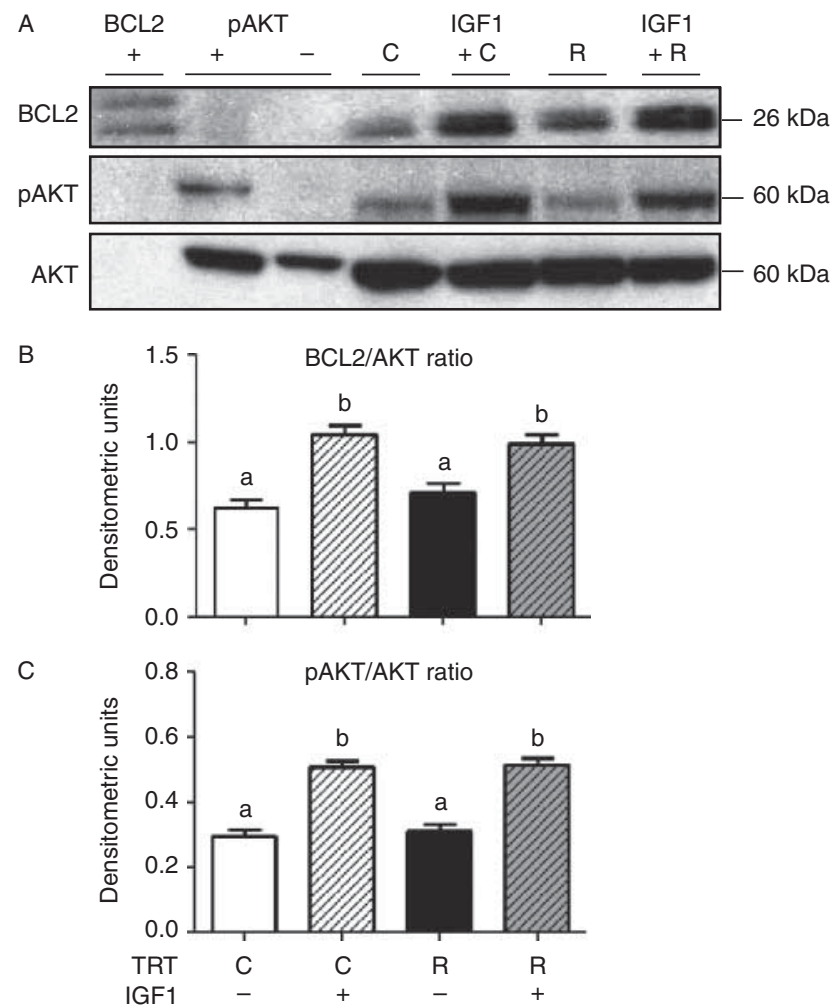

Figure 8 Effects of a single feeding of colostrum $(C)$ or milk replacer $(R)$, with $(+)$ or without $(-)$ oral IGF1, on cervical BCL2 and phosphorylated (p)AKT proteins at $12 \mathrm{~h}$ postnatal. Representative immunoblot $(\mathrm{A})$ images show positive $(+; \mathrm{BCL} 2$ and $\mathrm{pAKT})$ and negative ( - ; pAKT) control samples as described in 'Materials and methods' section. Densitometric data for the relative expression of BCL2 (B) and PAKT (C) were normalized to total AKT and expressed as $\mathrm{LSM} \pm$ s.E.M. Different letters indicate differences $(\mathrm{BCL} 2, P<0.05$ and pAKT, $P<0.001)$. 
prevents further transfer of macromolecules, including potential MbFs, across the Gl tract and into the neonatal circulation. Milk-replacer feeding can shorten the period from birth to gut closure to as early as $12 \mathrm{~h}$ postnatal (Jensen et al. 2001), thereby narrowing the window for MbF transfer. In parallel with such changes in GI tract function, changes in colostrum composition also occur within $48 \mathrm{~h}$ of parturition in the pig (Klobasa et al. 1987, Ogawa et al. 2014). Such changes may alter the nature and array of available lactocrine-active factors with potential to be transferred to the neonate by PND2. This is when replacer-fed gilts were returned to nursing in study 2 . The observation that mammotrope development was delayed throughout the prepubertal period when neonatal rats, deprived of lactation day 1 colostrum, were cross-fostered to dams on lactation day 7 supports this idea (Nusser \& Frawley 1997). Both changes in neonatal gut closure dynamics and colostrum composition over time may define the critical window for lactocrine signaling.

Results of study 3 , in which a single feeding of either colostrum or milk replacer was administered via orogastric gavage, confirm data reported in studies 1 and 2, indicating that colostrum consumption immediately after birth supports cervical cell proliferation. Furthermore, these data establish that such effects are detectable by $12 \mathrm{~h}$ postnatal. These observations provide the basis for the development of a $12 \mathrm{~h}$ bioassay protocol for evaluation of potential lactocrine-active factors. Data also indicate that IGF1 is orally active in the porcine neonate as reflected by the effects on cervical PCNA LI, as well as patterns of cervical BCL2 and pAKT expression.

A candidate MbF, IGF1, is present in the colostrum and milk of multiple species (Francis et al. 1988, Campbell \& Baumrucker 1989, Nagashima et al. 1990, Prosser et al. 1990, Donovan et al. 1991a,b), including the pig (Simmen et al. 1988). Similar to milk-borne relaxin (Frankshun et al. 2012), IGF1 concentrations in porcine milk are highest during the first few days of lactation and decline during the transition of colostrum into milk (Simmen et al. 1990b, Donovan et al. 1994). Milk-borne IGFs are present in free and bound states throughout lactation (Donovan et al. 1994, Xu \& Wang 1996). IGF-binding proteins (IGFBPs), present in porcine milk (Simmen et al. 1988, Donovan et al. 1994), function as transport molecules, increase the half-life of circulating IGF1 (Walton et al. 1989), and can modulate activity of IGF (Baxter 1988, McCusker et al. 1991).

Whether IGF1 administered orally can enter the neonatal porcine circulation remains unclear. Serum IGF1 concentrations did not differ between replacer-fed pigs with or without supplemental IGF1 for 4 days from birth when evaluated at 24, 48, 72, or $96 \mathrm{~h}$ postnatal (Burrin et al. 1996). Similarly, porcine serum IGF1 concentrations assessed on PND14 were unaffected by oral supplementation of IGF1 delivered in milk replacer (Houle et al. 2000). Nevertheless, both studies reported proliferative effects in the GI tract for IGF1-supplemented pigs (Burrin et al. 1996, Houle et al. 2000). By contrast, serum IGF1 concentrations in neonatal rats fed formula supplemented with IGF1 for 3 days were higher than those found in rats fed formula devoid of IGF1 (Philipps et al. 1997). In addition, when fed orally to pigs at birth or on PND3, ${ }^{125}$ I-IGF1, administered in colostrum, was detected in peripheral plasma within $1 \mathrm{~h}$ after administration, and was found in the stomach, small intestine, kidney, and other somatic tissues by $4 \mathrm{~h}$ post-administration (Xu \& Wang 1996). These results indicated that orally administered IGF1 can and does enter the neonatal circulation. Consistently, in a comparison with neonatal pigs that were either nursed or replacer-fed (Dauncey et al. 1994), nursed pigs displayed higher plasma IGF1 concentrations and increased growth rate. In that study, hepatic IGF1 levels were similar in nursed and replacer-fed pigs, suggesting that differences in plasma IGF1 concentrations were due to high levels of milk-borne IGF1 (Dauncey et al. 1994). Currently, the preponderance of data supports the idea that IGF1 acquired orally can enter the neonatal circulation. To the extent that this is the case, effects of orally administered IGF1 reported here could reflect direct actions of this peptide growth factor at the level of the cervix.

Oral IGF1 can stimulate the growth of neonatal porcine $\mathrm{Gl}$ tissues. In replacer-fed pigs, oral IGF1 promoted cell proliferation in intestinal crypts (Xu et al. 1994), increased jejunal and ileal villus height by PND4 (Burrin et al. 1996), and both jejunal villus height and mucosal DNA content and synthesis by PND14 (Houle et al. 2000). The present results indicate that the porcine cervix is also a target for oral IGF1. The extent to which these effects reflect direct actions of orally administered IGF1 at the level of the cervix or an alternate indirect mechanism (Baumrucker \& Blum 1993) is not known.

Supplementation of colostrum with IGF1 did not affect cervical cell proliferation. However, in replacer-fed gilts oral IGF1 administration increased cervical cell proliferation to levels equivalent to those observed for colostrum-fed gilts at $12 \mathrm{~h}$ postnatal. One explanation for these effects is that agents in colostrum that are absent in milk replacer, including IGFBPs (Donovan et al. 1994), caseins, and/or lactoferrin (Xian et al. 1995), may bind IGF1 and impede its uptake into the neonatal circulation, thereby reducing IGF1 bioavailability. The most abundant binding protein in peripheral circulation, IGFBP3 can bind substantial amounts of circulating IGF1, thereby increasing its half-life (Baxter 1991). Also present at high concentrations in the circulation of young pigs (Dauncey et al. 1993), IGFBP2, together with IGFBP3, could further affect the bioavailability of IGF1. To the extent that IGFBP profiles differ between colostrum-fed gilts and replacer-fed gilts, this could explain, in part, the proliferative responses of cervical 
cells seen in IGF1-supplemented, replacer-fed gilts, in which IGF1 bioavailability could be greater.

Cervical pAKT and BCL2 responses indicated that orally administered IGF1 was active in colostrum-fed gilts and replacer-fed gilts. IGF1 stimulates cell proliferation and promotes cell differentiation and survival through interactions with the IGF1 receptor and subsequent activation of signaling cascades involving the PI3K/AKT pathway (Woodgett 2005). A serine/ threonine kinase, AKT plays a role in inhibition of apoptosis by phosphorylating and inactivating several proteins involved in the apoptotic cascade (Dudek et al. 1997, Mora et al. 2005). Activated pAKT can increase the levels of anti-apoptotic proteins including BCL2 (Mora et al. 2005).

The fact that cervical pAKT and BCL2 expression levels were similar at $12 \mathrm{~h}$ postnatal in gilts given a single feeding of either colostrum or milk replacer at birth indicates that cervical expression of these molecules is not acutely lactocrine sensitive. In contrast to results obtained for cervical cell proliferation, oral IGF1 supplementation increased cervical pAKT and BCL2 expression regardless of the medium in which it was delivered. An explanation for these observations may be that PAKT and BCL2 responses are more sensitive to induction by IGF1. Reduced IGF1 bioavailability in colostrum (Simmen et al. 1988, Xian et al. 1995) could also contribute to differing results, as indicated above. Furthermore, the capacity of endogenous IGFBPs to bind additional, exogenous IGF1 can be limited by the degree of binding protein saturation (Umezawa et al. 1991). The extent to which agents in colostrum affect the bioavailability of IGF1 or other potentially lactocrine-active MbFs will be important to determine.

Taken together, the results presented in this study establish that, as reported for the neonatal porcine uterus (Miller et al. 2013) and testis (Rahman et al. 2014), as well as for the murine hippocampus (Liu et al. 2014), lactocrine support is necessary for normal development of the neonatal porcine cervix. Disruption of cervical development by transient imposition of the lactocrine-null state for 2 days from birth altered the cervical developmental program in a manner that, as assessed on PND14, could not be reversed by returning gilts to nursing in synchrony with their littermates. Evidence that effects of a single feeding of colostrum at birth can be detected in developing porcine cervical tissues by $12 \mathrm{~h}$ postnatal indicates that lactocrine regulation of postnatal events associated with cervical and, by extension, FRT development is initiated at first ingestion of colostrum. This observation provides the basis for the development of a more efficient bioassay for the identification of lactocrine-active MbFs. Present results also implicate IGF1, biologically active in the piglet, as a potential lactocrine-active factor affecting FRT development.

\section{Declaration of interest}

The authors declare that there is no conflict of interest that could be perceived as prejudicing the impartiality of the research reported.

\section{Funding}

This work was supported by USDA-NIFA NRI grants 200735203-18098 and 2013-67016-20523 and NSF-EPS-1158862.

\section{Acknowledgements}

The authors thank Laura Comerford, Felicia Kleiman, and Rebecca Potosky in the Rutgers Animal Care Program, Auburn Animal Care staff, Camp David, and the Rutgers undergraduate Sow Watch Club for their contributions to these studies.

\section{References}

Bartol FF \& Bagnell CA 2012 Lactocrine programming of female reproductive tract development: environmental connections to the reproductive continuum. Molecular and Cellular Endocrinology 354 16-21. (doi:10.1016/j.mce.2011.10.008)

Bartol FF, Wiley AA, Spencer TE, Vallet JL \& Christenson RK 1993 Early uterine development in pigs. Journal of Reproduction and Fertility $\mathbf{4 8}$ 99-116.

Bartol FF, Wiley AA, Floyd JG, Ott TL, Bazer FW, Gray CA \& Spencer TE 1999 Uterine differentiation as a foundation for subsequent fertility. Journal of Reproduction and Fertility 54 287-302.

Bartol FF, Wiley AA \& Bagnell CA 2008 Epigenetic programming of porcine endometrial function and the lactocrine hypothesis. Reproduction in Domestic Animals 43 (Suppl 2) 273-279. (doi:10.1111/j.14390531.2008.01174.x)

Bartol FF, Wiley AA, Miller DJ, Silva AJ, Roberts KE, Davolt ML, Chen JC, Frankshun AL, Camp ME, Rahman KM et al. 2013 Lactation Biology Symposium: lactocrine signaling and developmental programming. Journal of Animal Science 91 696-705. (doi:10.2527/jas.2012-5764)

Baserga R \& Rubin R 1993 Cell cycle and growth control. Critical Reviews in Eukaryotic Gene Expression 3 47-61.

Baumrucker CR \& Blum JR 1993 Secretion of insulin-like growth-factors in milk and their effect on the neonate. Livestock Production Science 35 49-72. (doi:10.1016/0301-6226(93)90181-G)

Baxter RC 1988 The insulin-like growth factors and their binding proteins. Comparative Biochemistry and Physiology. B, Comparative Biochemistry 91 229-235. (doi:10.1016/0305-0491(88)90137-X)

Baxter RC 1991 Insulin-like growth factor (IGF) binding proteins: the role of serum IGFBPs in regulating IGF availability. Acta Paediatrica Scandinavica. Supplement 372 107-114 (discussion 115). (doi:10.1111/ j.1651-2227.1991.tb17983.x)

Blum JW \& Baumrucker CR 2008 Insulin-like growth factors (IGFs), IGF binding proteins, and other endocrine factors in milk: role in the newborn. Advances in Experimental Medicine and Biology 606 397-422. (doi:10.1007/978-0-387-74087-4_16)

Burrin DG, Wester TJ, Davis TA, Amick S \& Heath JP 1996 Orally administered IGF-I increases intestinal mucosal growth in formula-fed neonatal pigs. American Journal of Physiology 270 R1085-R1091.

Campbell PG \& Baumrucker CR 1989 Insulin-like growth factor-I and its association with binding proteins in bovine milk. Journal of Endocrinology 120 21-29. (doi:10.1677/joe.0.1200021)

Cooke PS, Ekman GC, Kaur J, Davila J, Bagchi IC, Clark SG, Dziuk PJ, Hayashi K \& Bartol FF 2012 Brief exposure to progesterone during a critical neonatal window prevents uterine gland formation in mice. Biology of Reproduction 86 63. (doi:10.1095/biolreprod.111.097188)

Crain DA, Janssen SJ, Edwards TM, Heindel J, Ho SM, Hunt P, Iguchi T, Juul A, McLachlan JA, Schwartz J et al. 2008 Female reproductive 
disorders: the roles of endocrine-disrupting compounds and developmental timing. Fertility and Sterility 90 911-940. (doi:10.1016/ j.fertnstert.2008.08.067)

Dauncey MJ, Rudd BT, White DA \& Shakespear RA 1993 Regulation of insulin-like growth factor binding proteins in young growing animals by alteration of energy status. Growth Regulation 3 198-207.

Dauncey MJ, Burton KA \& Tivey DR 1994 Nutritional modulation of insulin-like growth factor-l expression in early postnatal piglets. Pediatric Research 36 77-84. (doi:10.1203/00006450-199407001-00013)

Donovan SM \& Odle J 1994 Growth factors in milk as mediators of infant development. Annual Review of Nutrition 14 147-167. (doi:10.1146/ annurev.nu.14.070194.001051)

Donovan SM, Hintz RL \& Rosenfeld RG 1991 a Insulin-like growth factors I and II and their binding proteins in human milk: effect of heat treatment on IGF and IGF binding protein stability. Journal of Pediatric Gastroenterology and Nutrition 13 242-253. (doi:10.1097/00005176199110000-00002)

Donovan SM, Hintz RL, Wilson DM \& Rosenfeld RG $1991 b$ Insulin-like growth factors I and II and their binding proteins in rat milk. Pediatric Research 29 50-55. (doi:10.1203/00006450-199101000-00010)

Donovan SM, McNeil LK, Jimenez-Flores R \& Odle J 1994 Insulin-like growth factors and insulin-like growth factor binding proteins in porcine serum and milk throughout lactation. Pediatric Research 36 159-168. (doi:10.1203/00006450-199408000-00005)

Dudek H, Datta SR, Franke TF, Birnbaum MJ, Yao R, Cooper GM, Segal RA, Kaplan DR \& Greenberg ME 1997 Regulation of neuronal survival by the serine-threonine protein kinase Akt. Science 275 661-665. (doi:10.1126/science.275.5300.661)

Eldridge-White R, Easter RA, Heaton DM, O'Day MB, Petersen GC, Shanks RD, Tarbell MK \& Sherwood OD 1989 Hormonal control of the cervix in pregnant gilts. I. Changes in the physical properties of the cervix correlate temporally with elevated serum levels of estrogen and relaxin. Endocrinology 125 2996-3003. (doi:10.1210/endo-125-6-2996)

Filant J, Zhou H \& Spencer TE 2013 Progesterone inhibits uterine gland development in the neonatal mouse uterus. Biology of Reproduction 146 141-149. (doi:10.1095/biolreprod.111.097089)

Fleming JM, Desury G, Polanco TA \& Cohick WS 2006 Insulin growth factor-I and epidermal growth factor receptors recruit distinct upstream signaling molecules to enhance AKT activation in mammary epithelial cells. Endocrinology 147 6027-6035. (doi:10.1210/en.2006-0349)

Francis GL, McNamara PJ, Filsell OH \& Ballard FJ 1988 Plasma half-lives of native and modified insulin-like growth factor-I in lambs. Journal of Endocrinology 117 183-189. (doi:10.1677/joe.0.1170183)

Frankshun AL, Ho TY, Reimer DC, Chen J, Lasano S, Steinetz BG, Bartol FF \& Bagnell CA 2011 Characterization and biological activity of relaxin in porcine milk. Reproduction 141 373-380. (doi:10.1530/REP-10-0401)

Frankshun AL, Chen J, Barron LA, Ho TY, Miller DJ, Rahman KM, Bartol FF \& Bagnell CA 2012 Nursing during the first two days of life is essential for the expression of proteins important for growth and remodeling of the neonatal porcine cervix. Endocrinology 153 4511-4521. (doi:10.1210/ en.2012-1329)

Gray CA, Taylor KM, Ramsey WS, Hill JR, Bazer FW, Bartol FF \& Spencer TE 2001 Endometrial glands are required for preimplantation conceptus elongation and survival. Biology of Reproduction 64 1608-1613. (doi:10.1095/biolreprod64.6.1608)

Hendry WJ III, Branham WS \& Sheehan DM 2004 Diethylstilbestrol versus estradiol as neonatal disruptors of the hamster (Mesocricetus auratus) cervix. Biology of Reproduction 70 1306-1316. (doi:10.1095/biolreprod.103.024992)

Houle VM, Park YK, Laswell SC, Freund GG, Dudley MA \& Donovan SM 2000 Investigation of three doses of oral insulin-like growth factor-I on jejunal lactase phlorizin hydrolase activity and gene expression and enterocyte proliferation and migration in piglets. Pediatric Research 48 497-503. (doi:10.1203/00006450-200010000-00013)

Jensen AR, Elnif J, Burrin DG \& Sangild PT 2001 Development of intestinal immunoglobulin absorption and enzyme activities in neonatal pigs is diet dependent. Journal of Nutrition 131 3259-3265.

Klobasa F, Werhahn E \& Butler JE 1987 Composition of sow milk during lactation. Journal of Animal Science 64 1458-1466.

Leece JG 1973 Effect of dietary regimen on cessation of uptake of macromolecules by piglet intestinal epithelium (closure) and transport to the blood. Journal of Nutrition 103 751-756.
Liu B, Zupan B, Laird E, Klein S, Gleason G, Bozinoski M, Gal Toth J \& Toth M 2014 Maternal hematopoietic TNF, via milk chemokines, programs hippocampal development and memory. Nature Neuroscience 17 97-105. (doi:10.1038/nn.3596)

Masters RA, Crean BD, Yan W, Moss AG, Ryan PL, Wiley AA, Bagnell CA \& Bartol FF 2007 Neonatal porcine endometrial development and epithelial proliferation affected by age and exposure to estrogen and relaxin. Domestic Animal Endocrinology 33 335-346. (doi:10.1016/j. domaniend.2006.07.002)

McCusker RH, Busby WH, Dehoff MH, Camacho-Hubner C \& Clemmons DR 1991 Insulin-like growth factor (IGF) binding to cell monolayers is directly modulated by the addition of IGF-binding proteins. Endocrinology 129 939-949. (doi:10.1210/endo-129-2-939)

McLachlan JA, Tilghman SL, Burow ME \& Bratton MR 2012 Environmental signaling and reproduction: a comparative biological and chemical perspective. Molecular and Cellular Endocrinology 354 60-62. (doi:10.1016/j.mce.2011.11.028)

Miller DJ, Wiley AA, Chen JC, Bagnell CA \& Bartol FF 2013 Nursing for 48 hours from birth supports porcine uterine gland development and endometrial cell compartment-specific gene expression. Biology of Reproduction 88 1-4. (doi:10.1095/biolreprod.112.105056)

Mora A, Sakamoto K, McManus EJ \& Alessi DR 2005 Role of the PDK1-PKB-GSK3 pathway in regulating glycogen synthase and glucose uptake in the heart. FEBS Letters $\mathbf{5 7 9}$ 3632-3638. (doi:10.1016/j.febslet. 2005.05.040)

Nagashima K, Itoh K \& Kuroume T 1990 Levels of insulin-like growth factor I in full- and preterm human milk in comparison to levels in cow's milk and in milk formulas. Biology of the Neonate 58 343-346. (doi:10.1159/ 000243289)

Neville MC, Morton J \& Umemura S 2001 Lactogenesis. The transition from pregnancy to lactation. Pediatric Clinics of North America 48 35-52. (doi:10.1016/S0031-3955(05)70284-4)

Nguyen DA, Parlow AF \& Neville MC 2001 Hormonal regulation of tight junction closure in the mouse mammary epithelium during the transition from pregnancy to lactation. Journal of Endocrinology 170 347-356. (doi:10.1677/joe.0.1700347)

Nusser KD \& Frawley S 1997 Depriving neonatal rats of milk from early lactation has long-term consequences on mammotrope development. Endocrine 7 319-323. (doi:10.1007/BF02801325)

Ogawa S, Tsukahara T, Nishibayashi R, Nakatani M, Okutani M, Nakanishi N, Ushida K \& Inoue R 2014 Shotgun proteomic analysis of porcine colostrum and mature milk. Animal Science Journal 85 440-448. (doi:10.1111/asj.12165)

Peaker M 2002 The mammary gland in mammalian evolution: a brief commentary on some of the concepts. Journal of Mammary Gland Biology and Neoplasia 7 347-353. (doi:10.1023/A:1022860 902083)

Philipps AF, Anderson GG, Dvorak B, Williams CS, Lake M, Lebouton AV \& Koldovsky O 1997 Growth of artificially fed infant rats: effect of supplementation with insulin-like growth factor I. American Journal of Physiology 272 R1532-R1539.

Prosser CG, Fleet IR, Corps AN, Froesch ER \& Heap RB 1990 Increase in milk secretion and mammary blood flow by intra-arterial infusion of insulin-like growth factor-I into the mammary gland of the goat. Journal of Endocrinology 126 437-443. (doi:10.1677/joe.0.1260437)

Rahman K, Lovich JE, Lam C, Camp ME, Wiley AA, Bartol FF \& Bagnell CA 2014 Nursing supports neonatal porcine testicular development. Domestic Animal Endocrinology 48 84-92. (doi:10.1016/j.domaniend. 2014.02.006)

Rehfeldt C \& Kuhn G 2006 Consequences of birth weight for postnatal growth performance and carcass quality in pigs as related to myogenesis. Journal of Animal Science 84 (Suppl) E113-E123.

Ryan PL, Baum DL, Lenhart JA, Ohleth KM \& Bagnell CA 2001 Expression of uterine and cervical epithelial cadherin during relaxin-induced growth in pigs. Reproduction 122 929-937. (doi:10.1530/rep.0. 1220929)

Shelton JG, Steelman LS, White ER \& McCubrey JA 2004 Synergy between PI3K/Akt and Raf/MEK/ERK pathways in IGF-1R mediated cell cycle progression and prevention of apoptosis in hematopoietic cells. Cell Cycle 3 372-379. 
Simmen FA, Simmen RC \& Reinhart G 1988 Maternal and neonatal somatomedin C/insulin-like growth factor-I (IGF-I) and IGF binding proteins during early lactation in the pig. Developmental Biology 130 16-27. (doi:10.1016/0012-1606(88)90409-5)

Simmen FA, Cera KR \& Mahan DC 1990a Stimulation by colostrum or mature milk of gastrointestinal tissue development in newborn pigs. Journal of Animal Science 68 3596-3603.

Simmen FA, Whang KY, Simmen RC, Peterson GA, Bishop MD \& Irvin KM $1990 b$ Lactational variation and relationship to postnatal growth of insulin-like growth factor-I in mammary secretions from genetically diverse sows. Domestic Animal Endocrinology 7 199-206. (doi:10.1016/ 0739-7240(90)90026-V)

Tarleton BJ, Wiley AA \& Bartol FF 2001 Neonatal estradiol exposure alters uterine morphology and endometrial transcriptional activity in prepubertal gilts. Domestic Animal Endocrinology 21 111-125. (doi:10.1016/S0739-7240(01)00106-0)

Tseng YH, Ueki K, Kriauciunas KM \& Kahn CR 2002 Differential roles of insulin receptor substrates in the anti-apoptotic function of insulinlike growth factor-1 and insulin. Journal of Biological Chemistry 277 31601-31611. (doi:10.1074/jbc.M202932200)

Umezawa T, Ohsawa Y, Miura Y, Kato H \& Noguchi T 1991 Effect of protein deprivation on insulin-like growth factor-binding proteins in rats. British Journal of Nutrition 66 105-116. (doi:10.1079/BJN19910014)

Vallet JL, Miles JR \& Rempel LA 2013 A simple novel measure of passive transfer of maternal immunoglobulin is predictive of preweaning mortality in piglets. Veterinary Journal 195 91-97. (doi:10.1016/j.tvjl. 2012.06.009)

Walton PE, Gopinath R, Burleigh BD \& Etherton TD 1989 Administration of recombinant human insulin-like growth factor I to pigs: determination of circulating half-lives and chromatographic profiles. Hormone Research 31 138-142. (doi:10.1159/000181103)
Winn RJ, O'Day-Bowman MB \& Sherwood OD 1993 Hormonal control of the cervix in pregnant gilts. IV. Relaxin promotes changes in the histological characteristics of the cervix that are associated with cervical softening during late pregnancy in gilts. Endocrinology 133 121-128.

Woodgett JR 2005 Recent advances in the protein kinase B signaling pathway. Current Opinion in Cell Biology 17 150-157. (doi:10.1016/j. ceb.2005.02.010)

Xian CJ, Shoubridge CA \& Read LC 1995 Degradation of IGF-I in the adult rat gastrointestinal tract is limited by a specific antiserum or the dietary protein casein. Journal of Endocrinology 146 215-225. (doi:10.1677/joe. $0.1460215)$

Xu RJ \& Wang T 1996 Gastrointestinal absorption of insulin like growth factor-I in neonatal pigs. Journal of Pediatric Gastroenterology and Nutrition 23 430-437. (doi:10.1097/00005176-199611000-00013)

Xu RJ, Mellor DJ, Birtles MJ, Breier BH \& Gluckman PD 1994 Effects of oral IGF-I or IGF-II on digestive organ growth in newborn piglets. Biology of the Neonate 66 280-287. (doi:10.1159/000244118)

Yan W, Wiley AA, Bathgate RA, Frankshun AL, Lasano S, Crean BD, Steinetz BG, Bagnell CA \& Bartol FF 2006 Expression of LGR7 and LGR8 by neonatal porcine uterine tissues and transmission of milk-borne relaxin into the neonatal circulation by suckling. Endocrinology 147 4303-4310. (doi:10.1210/en.2006-0397)

Received 19 May 2014

First decision 8 July 2014

Revised manuscript received 24 July 2014

Accepted 29 July 2014 